\title{
What Determines Debt Maturity?
}

Rodolfo E. Manuelli

What determines the maturity structure of debt? In this article, I develop a simple model to explore how the optimal maturity of debt issued by a firm (or a country) depends both on the firm's cyclical state and other features of the economic environment in which it operates.

I find that firms with better current earnings and better growth prospects issue debt with longer maturity, while firms operating in more-volatile environments issue debt with shorter maturity. Yield to maturity is a poor indicator of the risk of debt issued by a firm. The reason is simple: Yield to maturity captures both default risk and a component that is a pseudo term premium. In the model, the market does require a term premium and one appears only because of the risk of default. It is not possible to separate the impact of maturity and risk. (JEL G12, G30)

Federal Reserve Bank of St. Louis Review, Third Quarter 2019, 101(3), pp. 155-76. https://doi.org/10.20955/r.101.155-76

\section{INTRODUCTION}

It is a standard view that borrowing short term exposes debtors-both firms and countries-to potential refinancing shocks. In some cases, the existence of short-term debt has been blamed for the subsequent poor performance of the borrower. In the case of the domestic financial system, the mismatch between (short) liabilities and (long) assets is sometimes viewed as a factor that explains the deep Financial Crisis of 2007-09 (see, for example, Brunnermeier and Oemkhe, 2013). Kacperczyk and Schnabl (2010) review the evidence of the role that commercial paper (which is short-term debt) played in the Finacial Crisis. In the case of sovereign debt, Rodrik and Velasco (1999) argue that short-term debt increases the likelihood of a crisis. Benmelech and Dvir (2011) document how East Asian countries shortened the maturity of their debt before the financial crisis in the 1990s. Broner, Lorenzoni, and Schmukler (2013) find that during crisis times it is optimal for countries to issue short-term debt.

Why do some firms (and countries) borrow short and others long? There is some evidence that shows that firms (or countries) that find themselves in a "weak" position at the time they

Rodolfo E. Manuelli is a professor of economics at Washington University in St. Louis and a research fellow at the Federal Reserve Bank of St. Louis. The author thanks Sid Sanghi for excellent research assistance and the Federal Reserve Bank of St. Louis for financial support.

(c) 2019, Federal Reserve Bank of St. Louis. The views expressed in this article are those of the author(s) and do not necessarily reflect the views of the Federal Reserve System, the Board of Governors, or the regional Federal Reserve Banks. Articles may be reprinted, reproduced, published, distributed, displayed, and transmitted in their entirety if copyright notice, author name(s), and full citation are included. Abstracts, synopses, and other derivative works may be made only with prior written permission of the Federal Reserve Bank of St. Louis. 
need to borrow-for example, when their current income is relatively low-tend to issue relatively short-term debt. In some cases, this has been interpreted as the cause of a subsequent default. This simplistic interpretation hinges on the observation that, since default is caused by the inability of a firm or a country to repay its debt and had the firm or country issued longterm debt, it would have had "more time" to recover and default could have been avoided.

If we are going to go beyond simplistic interpretations of observed correlations, a theory of the factors that determine the choice of maturity is needed. In addition to such a theory's ability to rationalize the evidence, having it is important from the point of view of a policymaker to the extent that it describes the supply of debt for different maturities as a function of economic variables.

The literature on firms' choice of maturity includes the early work by Diamond (1991) and Leland and Toft (1996). Recent work on default risk over the cycle in the corporate sector includes Chen et al. (2017). In the sovereign debt literature, Arellano and Ramanarayanan (2013) determine maturity as a function of the costs of different types of debt. Aguiar et al. (2019), following Arellano and Ramanarayanan (2013), show that a country that has issued long and short bonds and needs to reduce its debt should not intervene in the market for long bonds and make the adjustment using exclusively short-term debt.

In this article, I develop a simple model of the choice of the structure of debt by a risk neutral firm that needs to raise a certain level of funds. I restrict the analysis to the case of a pure discount bond. 1 I assume that the borrower and the financial market share exactly the same discount factor, that they are both risk neutral, and that information is complete. Thus, the choice of debt structure does not depend on differences in the valuation of risks between borrowers and lenders. Finally, I consider the case in which the borrower issues one bond. This eliminates the incentive that borrowers might have to issue short-term debt to dilute the value of long-term liabilities. I do not believe that strategic factors and differences in valuation criteria between borrowers and lenders are unimportant. Rather, I want to emphasize that factors other than those related to valuation and strategic considerations are also relevant to determine the maturity of the debt.

Even though the analysis could be applied to the study of sovereign debt (in this interpretation the borrower in the model is a country), I will assume that the borrower is a firm. This is mostly for convenience and to keep the presentation simple.

I find that there are several factors that influence the optimal (from the point of view of the borrower) maturity of the debt:

(i) The cyclical component. Firms that have better prospects (as measured by their current earnings) issue longer-term debt, as do firms with better growth prospects.

(ii) The market environment. Firms that operate in more-volatile environments choose to issue shorter-term debt.

(iii) Asset saleability. Firms that have high collateral-measured as the market value of their assets in the case of default-also issue longer-term debt.

The intuition underlying these results is somewhat complex. Consider first the impact on the market value of a debt instrument of a given maturity and face value of an increase in 
current income of the issuer. To the extent that income is positively serially correlated, the increase in current income increases expected future income, lowering the risk of default and, consequently, increasing the market value of the debt. However, a borrower that needs to raise a given amount has the opportunity to redesign the debt instrument to lower the debt's market value to match the financing needed. To this end, the borrower can (and does) increase the maturity (and the face value of the bond), reducing the market value of the debt to the desired level. In the context of the economy that I study, causality runs from the state of the borrower (in this case, the level of current earnings) to maturity: Lower current income induces the borrower to issue shorter-term debt, even when it was possible to issue longer-term debt. This choice is not driven by risk aversion on the part of lenders 2 but rather by the changes in the default risk associated with lower current income.

The impact of higher uncertainty about the growth rate of the firm's income has exactly the opposite effect as an increase in earnings. Higher uncertainty increases the risk of default, lowering the market value of the debt. For a given financing need, the borrower has to change the structure of the debt to restore the debt's market value, which can be accomplished by lowering the expected maturity.

Finally, a higher level of collateral increases the market value of the debt (it lowers the cost of default from the point of view of the debt holders and, hence, the price of risk). In order to reduce this value to match the financing needed, the firm finds it optimal to increase the price of risk by lengthening the expected maturity of the debt it issues.

\section{REVIEW OF EMPIRICAL FINDINGS}

There is a large empirical literature on the factors that influence debt maturity of business firms. In a recent paper, Manuelli and Sanchez (2019) provide a short review of this literature and perform an up-to-date empirical analysis using data on nonfinancial and nonregulated firms in Standard \& Poor's Compustat dataset. $\underline{3}$ They define maturity as the ratio of debt with maturity of less than five years to total debt. Table 1 reports some of their results.

Manuelli and Sanchez's (2019) results parallel many others in the literature. They find that firms that operate in more-uncertain environments, as measured by the different volatility measures that they compute, decrease the maturity of the debt (that is, they increase the share of short-term debt). In their sample, asset maturity-measured as a weighted average of shortand long-term assets-does not have a significant impact on maturity. In this sample, there is very little evidence of "matching" the maturity of the asset with the liabilities of the firm. Asset salability - measured as the ratio of total net property, plant, and equipment to total assetshas a significant impact on maturity. I interpret this as indicating that firms that have assets that can be more easily sold in the market (as opposed to firms whose assets have a large intangible component) choose to issue longer-term debt. Finally, size-measured here by sales-has a positive impact on maturity: Firms with higher sales tend to issue, on average, longer-term debt.

The results reported here are consistent with the findings of Dinlersoz et al. (2018), who use a large data set that includes both traded and private firms. They find, in a cross section, that larger firms choose a higher ratio of long-term to short-term debt. Moreover, maturity- 


\section{Table 1}

\section{Dependent Variable: Ratio of Short-Term Debt}

\begin{tabular}{lccc} 
R\&D investment & $-0.0102^{*}$ & $-0.0139^{*}$ & $-0.1250^{*}$ \\
\hline Volatility (sales) & $0.0945^{* * *}$ & & \\
\hline Volatility (EBITDA) & & & \\
\hline Volatility (returns) & & $-1249^{* * *}$ & $0.0097^{* * *}$ \\
\hline Asset maturity & -0.0009 & -0.0010 & -0.0009 \\
\hline Asset salability & $-0.1596^{* * *}$ & $-0.1601^{* * *}$ & $-0.1631^{* * *}$ \\
\hline Size & $-0.0404^{* * *}$ & $-0.0405^{* * *}$ & $-0.0394^{* * *}$ \\
\hline Year fixed effect & Yes & Yes & Yes \\
\hline Industry fixed effect & Yes & Yes & Yes \\
\hline No. observations & 17,169 & 17,169 & 17,169 \\
\hline$R^{2}$ & 0.19 & 0.19 & 0.19
\end{tabular}

NOTE: *****, and * indicate significance at the 1,5, and 10 percent levels, respectively. EBITDA, earnings before interest and taxes.

SOURCE: Manuelli and Sanchez (2019).

proxied by the ratio of long-term to short-term debt-is higher for firms that have higher collateral, measured as the ratio of tangible assets to fixed assets.

The take away from the empirical evidence can be summarized as follows:

- Firms that have higher profits, income, and are larger on average issue longer-term debt.

- Firms that operate in more-volatile environments-for example, as measured by the standard deviation of sales or net income-tend to issue shorter-term debt.

- Firms that can provide better collateral tend to issue longer-term debt.

There is also a fairly significant literature that studies the factors that influence the maturity structure of sovereign debt (see, for example, the discussion in Dvorkin et al., 2018). Sometimes in the literature-especially in the case of sovereign debt-the correlation between maturity and the state of the country is interpreted as reflecting a specific direction of causality. More precisely, in the presence of possible interruptions in funding, countries are advised to "borrow long." Moreover, it is not uncommon for countries whose income is low to refinance existing debt using shorter maturities. In this article, I will argue that it is possible that causality goes in the opposite direction: When income is low-and in this model this implies that the probability of default is high-firms choose to issue shorter debt even though the market was willing to lend longer. The reason is simple: The price that the market charges for high-maturity bonds makes them less attractive than short-maturity bonds. ${ }^{4}$

In what follows, I present a model that captures the stylized facts listed above and that is useful to disentangle the role played by different economic factors in determining the optimal structure of debt. 


\section{THE MODEL}

I study the case of a risk-neutral firm that has to incur an irreversible cost to implement an investment project. I assume that the returns of the project are completely described by a few parameters that determine the associated stochastic processes for net output (or earnings). I denote net earnings by $x_{t}$, and I assume that they evolve according to the following stochastic differential equation:

$$
d x_{t}=\mu x_{t} d t+\sigma x_{t} d W_{t}
$$

where $W_{t}$ is a Wiener process or Brownian motion and $\mu$ (the expected growth rate) and $\sigma$ (the volatility of the growth rate) are constants.

I assume that $x_{t}$ is known at all times by all market participants.

Given that the stochastic process for net income is nonnegative, in the absence of debt obligations, it is efficient for this firm to operate forever. In this case, the unlevered value of the firm is

$$
V^{*}(x)=E\left[\int_{0}^{\infty} e^{-r t} x_{t} d t \mid x_{0}=x\right]=\frac{x}{r-\mu} .
$$

\subsection{The Value of the Firm}

I assume that the firm has to finance either part or all of the cost of the project by issuing noncontingent debt. The firm has access to a risk-neutral credit market that will price any debt issued by the firm, using the same discount rate, $r$. Thus, none of the results are driven by either differences in the discount factor or differences in the curvature of direct payoffs.

I consider debt in the form of pure discount bonds with stochastic maturity. Thus, a debt instrument is completely described by two parameters: $T$, the expected maturity, and $K$, the face value that must be paid at maturity. I assume that maturity arrives as a Poisson process with rate $\eta=1 / T$. I also assume that if the firm defaults on its debt, bondholders receive a fraction $1-\delta$ of the unlevered value of the firm.

The value of a firm that has issued a $(K, T)$ bond is

$$
V(x ; T, K)=\left\{E \int_{0}^{N_{T}} e^{-r t} x_{t} d t+e^{-r N_{T}} \max \left(\frac{x_{N_{T}}}{r-\mu}-(K+F), 0\right) \mid x_{t}=x\right\} .
$$

Here $N_{T}$ is the first time that the Poisson process with parameter $1 / T$ jumps. I assume that, at maturity, there is a cost of repaying the debt, which is captured by $F$. In this simple model that ignores refinancing, this feature is necessary to prevent the firm from issuing an extremely short bond. $\underline{5}$

The first term in equation (1) is the value of earnings until the debt matures, while the second term is the residual value of the firm. The residual value of the firm is either the unlevered value minus the face value of the debt or zero in the case of default. The optimal default rule at maturity is very simple: Default if and only if 


$$
\frac{x_{N_{T}}}{r-\mu}<K
$$

that is, if the value of the assets falls short of the face value of the outstanding debt. Let the value of income that triggers a default be denoted as $\bar{x}(K)$. Thus,

$$
\bar{x}(K)=(r-\mu) K
$$

Since the face value of the debt is a choice variable of the firm, the default decision is endogenous.

The appendix shows that the value of the firm, $V(x ; T, K)$ can be split into two branches. The upper branch, $V_{H}(x, T, K)$, which corresponds to $x \geq \bar{x}(K)$, gives the value of the firm when the debt that it has issued is "in the money," while the lower branch, $V_{L}(x, T, K)$, reports the equity value when the debt is "out of the money"; that is, if the debt matures when earnings are in this (low) region, the firm's optimal choice is to default.

The expressions show that the value of the firm depends on the cyclical component, as captured by the value of net earnings, $x$. The appropriate expressions are

$$
\begin{aligned}
& V_{H}(x, T, K)=\frac{x}{r-\mu}-\frac{(K+F)}{1+T r}+\bar{V}_{H}^{1}\left(\frac{x}{\bar{x}(K)}\right)^{\lambda_{1}}, \text { if } x \geq \bar{x}(K), \\
& V_{L}(x, T, K)=\frac{T x}{1+T(r-\mu)}+\bar{V}_{L}^{2}\left(\frac{x}{\bar{x}(K)}\right)^{\lambda_{2}}, \text { if } x \leq \bar{x}(K),
\end{aligned}
$$

where the constants $\bar{V}_{H}^{1}$ and $\bar{V}_{L}^{2}$ depend in a very nonlinear way on the parameters of the model. The appendix provides details.

The expressions illustrate the role of default. Consider, for example, the value of the equity in this firm in "good times." The value can be split into two components. The first term,

$$
\frac{x}{r-\mu}-\frac{(K+F)}{1+T r}
$$

gives the expected present discounted value of earnings minus the default-free value of the debt. The second term,

$$
\bar{V}_{H}^{1}\left(\frac{x}{\bar{x}(K)}\right)^{\lambda_{1}}
$$

-the appendix shows that $\bar{V}_{H}^{1}$ is positive-implies that the value of the firm is higher than what the computation that ignores default would suggest: This term captures the option that the firm has to default and avoid paying the principal on the debt.

\subsection{The Valuation of the Debt}

The value of the bond issued by the firm is

$$
B(x ; T, K)=E\left[e^{-r N_{T}} R\left(x_{N_{T}}\right) \mid x_{t}=x\right],
$$


where

$$
R_{B}\left(x_{N_{T}}, K, \delta\right)=\left\{\begin{array}{ll}
K & \text { if } x_{N_{T}} \geq \bar{x}(K) \\
(1-\delta) \frac{x_{N_{T}}}{r-\mu} & \text { if } x_{N_{T}}<\bar{x}(K)
\end{array} .\right.
$$

Thus, if net earnings of the firm are high, bond holders receive payoff $K$ if $x_{N_{T}} \geq \bar{x}(K)$, while if net earnings are low, bond holders receive the fraction $1-\delta$ of the unlevered value of the firm.

For future reference, the value of a $(T, K)$ bond in the absence of default risk is

$$
B^{*}(T, K)=\frac{K}{1+r T} .
$$

In this model, the firm and the market discount cash flows at exactly the same rate. Thus, the choice of maturity cannot be driven by different perceptions of risk as reflected in the stochastic discount factor. Moreover, the market does not charge a "term premium." The discount rate, $r$, is constant and independent of the maturity of the bond. Of course, in the presence of default, there will be a pseudo term premium, but this is endogenous and determined by the choices made by the firm.

\subsection{Choosing the Optimal Debt Structure}

The problem faced by a firm that has to raise $\bar{K}$ is

$$
\max _{(T, K)} V(x, T, K)
$$

subject to the constraint that the debt issued raises at least $\bar{K}$; that is,

$$
B(x, T, K) \geq \bar{K}
$$

The appendix describes the functions $V(x, T, K)$ and $B(x, T, K)$.

The problem faced by the firm is fairly nonlinear, and I present some results about the optimal debt structure in the quantitative section. However, by exploring how different factors affect the price of risk, it is possible to gain intuition on how they influence the optimal choice of debt structure.

To illustrate the mechanism, I concentrate on the case in which the firm issues a bond that is in the money, that is, a bond that if matured instantaneously would be repaid.

The value of a bond in this "high" region can be written as

$$
B_{H}(x, T, K)=B^{*}(T, K)\left[1-P_{H}(x, T, K)\right] .
$$

In this setting $P_{H}(x, T, K)$ can be interpreted as the (proportional) price of risk of a $(T, K)$ bond issued by a firm with current earnings given by $x$. In the appendix, I show how $P_{H}(x, T, K)$ depends on specific factors. In particular, this price of risk can be decomposed as

$$
P_{H}(x, T, K)=\Phi^{H}(T, K) E\left[e^{-r T_{\bar{x}(K)}} \mid x\right],
$$


where $T_{\bar{x}(K)}$ is the first time that the process for net earnings hits the value $\bar{x}(K)$ given that $x>\bar{x}(K)$. Formally, this "stopping time" is given by

$$
T_{\bar{x}(K)} \equiv \inf \left\{t: x_{t}=\bar{x}(K)\right\} .
$$

Recall that if the bond matures and $x<\bar{x}(K)$, the firm will default, while if $x \geq \bar{x}(K)$, the bond will be repaid. Thus, I interpret $E\left[e^{-r T_{\bar{x}(K)} \mid x}\right]$ as the expected present discounted value of a dollar payable when the borrower's net earnings reach the default threshold. The higher this value, the higher the risk, as the payoff depends on the borrower reaching the default state.

Equation (4) describes the price of risk for a bond that is in the money. This price of risk, in turn, depends on the following:

- The state of the firm, as measured by the level of current net income. Thus, a higher value of $x$ corresponds to a firm that needs to issue debt in "good" times, while a lower value of $x$ captures the impact of negative cyclical conditions. In the context of this simple model, the level of current net earnings, $x$, captures the impact of cyclical conditions on risk.

- The features of the economic environment. In this model, these features are completely summarized by the interest rate, $r$; the mean growth rate of the firm's earnings, $\mu$; and the volatility of the growth rate, $\sigma$. Increases in $\mu$ correspond to better growth prospects, while increases in $\sigma$ are interpreted as capturing higher uncertainty in the earnings process. $\underline{6}$

- The structure of the debt as captured by the face value, $K$, and the expected maturity, $T$.

The formulas in the appendix show that all those elements interact in a fairly nonlinear manner to determine the price of risk.

Before I describe how those factors influence the riskiness of the debt, it is useful to compute the yield to maturity, $y$, of a bond. It is defined as the discount rate, $y$, that makes the value of a $(T, K)$ bond with a zero default rate equal to the market value of the debt of that same $(T, K)$ bond when the issuer optimally defaults. Formally, when the bond is in the money (when $x \geq \bar{x}(K)$, which I view as the normal case), $y$ satisfies

$$
\frac{K}{1+y T}=B_{H}(x, T, K) \text {. }
$$

This equation is equivalent to

$$
\frac{K}{1+y T}=\frac{K}{1+r T}\left[1-P_{H}(x, T, K)\right] .
$$

Then, the excess of the yield to maturity over the risk-free interest rate is

$$
y-r=\left(r+\frac{1}{T}\right)\left(\frac{P_{H}(x, T, K)}{1-P_{H}(x, T, K)}\right) .
$$


Thus, there is a direct connection between the price of risk, $P_{H}(x, T, K)$, and the excess yield that the debt commands. Similar formulas apply to bonds that are out of the money (i.e., when $x<\bar{x}(K))$; the details can be found in the appendix.

\subsection{Cyclical Effects}

What is the impact of the current level of earnings on the price of risk of a given $(T, K)$ bond? Since $P_{H}(x, T, K)=\Phi^{H}(T, K) E\left[e^{-r T_{\bar{x}(K)}} \mid x\right]$, the only term that depends on $x$ is $E\left[e^{-r T_{\bar{x}(K)} \mid x}\right]$. Higher values of $x$ increase the time until $x$ reaches $\bar{x}(K)$ (recall that $x \geq \bar{x}(K)$ ), which is the level of net earnings at which the firm defaults. Thus, higher current earnings lower the risk of default by making the expected value of the random discount factor lower.

\subsection{Economic Environment}

Simple but tedious algebra show that increases in the growth prospects, $\mu$, decrease the price of risk. There are two forces at work. First, higher growth increases the unlevered value of the firm, $V^{*}(x)$, for any given level of earnings, $x$. Since default occurs when the unlevered value of the firm is lower, a higher $\mu$ lowers the cost of default. A factor that lowers the price of risk is that net earnings "grow away" from $\bar{x}(K)$ at a faster rate the higher the value of $\mu$. Thus, the expected value of the random discount factor increases.

Increases in $\sigma$ correspond to a lower market value of the assets in case of default. The formulas in the appendix show that increases in $\delta$ are associated with higher risk prices. The intuitive argument is that a lower value of the marketable assets in case of default (higher $\delta$ ) implies that the cost of default (from the point of view of the debt holder) is higher and, hence, the firm is assessed a higher price by the market.

Consider next the effect of uncertainty. It is possible to show that the price of risk is increasing in the level of uncertainty. There are two components. An increase in $\sigma$ decreases the time to reach the default level (and has the opposite effect of an increase in $\mu$ ). Thus, $E\left[e^{-r T_{\bar{X}(K)} \mid x}\right]$ increases and converges to 1 as $\sigma$ increases without bound. The second component, $\Phi_{H}(T, K)$, increases as well, and its limit, when $\sigma \rightarrow \infty$, is also 1 . Thus, higher uncertainty increases the price of risk (and the excess yield of any bond) and the price of risk converges to 1 as $\sigma$ grows (the excess yield, $y-r$, goes to infinity). To sum up, the market value of debt decreases when uncertainty increases because the price of risk increases.

\subsection{The Structure of the Debt}

The impact of a high face value on the price of risk is pretty intuitive: Higher $K$ increases the default threshold, $\bar{x}(K)$. This, in turn, increases the present value of the stochastic discount factor, $E\left[e^{-r T_{\bar{x}(K)} \mid x}\right]$, and the price of risk. The impact of longer maturities is less straightforward. Consider first a bond of very short maturity. Formally, take the limit as $T$ goes to zero. In this case, the bond matures instantly and, given that the firm is in the no-default zone, there is no risk; the price $P_{H}(x, T, K)$ is zero. This bond also has $y=r$, that is, no premium. As $T$ increases, the effects are more complicated. A longer maturity has an impact similar to a lower discount factor and pushes the term $E\left[e^{-r T_{\bar{x}(K)}} \mid x\right]$ up. It also increases the first component. It 
is possible to show that as $T$ grows without bound, the price of risk converges to a positive number less than 1.

\subsection{The Excess Yield}

In the finance literature, it is standard to interpret the excess yield of a bond in terms of a "term premium" - the higher return that a longer bond has to offer-and a "risk premium" the higher return associated with the risk of default. In this model, attempting to decompose the excess yield, $y-r$, into a term premium and a risk premium would be somewhat misleading. To see this, assume that there is no default. One way of capturing no default is to drive the current level of income to infinity. The discussion of the impact of $x$ on the price of risk shows that the price of risk goes to zero and hence $y$ converges to $r$. In this model, the market does not charge a term premium. There is a premium that responds to the maturity of the bond, but it is not a pure term premium: It critically depends on risk.

How does the excess yield of a given $(T, K)$ bond depend on cyclical factors? Simple algebra shows that the elasticity of the excess yield with respect to $x$ is given by

$$
\frac{\partial \ln (y-r)}{\partial \ln (x)}=\frac{\lambda_{1}\left(T, \sigma^{2}\right)}{1-P_{H}(x, T, K)},
$$

where $\lambda_{1}\left(T, \sigma^{2}\right)$ is defined in the appendix. The term $\lambda_{1}\left(T, \sigma^{2}\right)$ is negative, and it increases (becomes less negative) when $\sigma$ increases and decreases when expected maturity, $T$, increases.

Since $P_{H}(x, T, K)$ is decreasing in $x$, the model implies that the excess yield when income is low is not only higher but also much more responsive to "news" about income. In the case of firms with low current income, small increases in income have a potentially large impact on the excess yield. At the other end, when the firm issuing the debt has a high level of current income, small changes in that level have a smaller impact on the excess yield. ${ }^{?}$

Uncertainty also impacts the excess yield. In this model, the (instantaneous) standard deviation of the growth rate of income is given by $\sigma$. Since higher $\sigma$ increases $P_{H}(x, T, K)$, it, in turn, increases the excess yield. The model implies that firms that operate in more-uncertain environments will have to offer a higher return for similar bonds. $\stackrel{8}{ }$ Note that this implication is restricted to a given bond, that is, for a fixed $(T, K)$. It does not necessarily imply that higher volatility and observed yields are positively correlated, since a firm that faces a more uncertain environment can choose a different structure of its debt, that is, a different $(T, K)$ bond.

\subsection{Environment Changes and the Structure of Debt}

In this section, I offer a heuristic discussion that suggests how changes in the environment affect the structure of debt. The next section uses a quantitative version of the model to display the impact of changes in the economic environment faced by the firm.

It is useful to consider the situation of a borrower that has chosen the debt structure optimally - that is, it has chosen a bond $(T, K)$ that maximizes the equity value and raises the necessary amount of resources - and that, unexpectedly, finds itself in a different environment. In this case, I ask, what is the likely response of the firm to the change in conditions-that is, what is the "new" $(T, K)$ bond the firm would like to issue. 
To get some intuition about the forces at work, it is useful to describe the connection between the structure of the debt and the debt's market value in elasticity form. The appropriate expressions are (with the arguments omitted to keep the expressions simple)

$$
\frac{\partial B_{H}}{\partial K} \frac{K}{B_{H}}=1+\frac{\lambda_{1} P_{H}}{1-P_{H}}
$$

and

$$
\frac{\partial B_{H}}{\partial T} \frac{T}{B_{H}}=\frac{T}{1+r T}\left[-1-\frac{\partial P_{H} / \partial T}{1-P_{H}}\right] .
$$

Consider first an improvement in current income. It lowers the price of risk, $P_{H}$, and increases the value of the "existing" debt. Thus, the firm that has a fixed demand for funds needed to restructure the debt to lower the debt's value to the level it was before the increase in income. This can be done by lengthening the maturity of $T$ or increasing the face value of $K$. The previous expressions show that longer maturity always lowers the value of the debt, while a higher face value lowers the value of the debt only when net income is low since, as $x$ goes to infinity, the impact of higher $K$ is positive. Thus, we tentatively expect higher $x$ to result in longer maturity and a higher face value.

Consider next the impact of an unexpected increase in uncertainty. It lowers the market value of the existing debt, and, in this case, the firm needs to adjust the structure of the debt, $(T, K)$, so as to increase the debt's value. This can be accomplished by shortening the maturity and decreasing the face value.

As it is clear from the equations, the impact of features of the environment on the valuation of the firm and the bond is fairly nonlinear. Instead of a somewhat boring derivation of the impact, I report the results from a quantitative exercise.

\section{QUANTITATIVE MODEL}

In this section, I report the implications of the model for the expected maturity of the debt, as measured by $T$ as a function of the cyclical state, as captured by $x$, and other features of the environment that do not change with the cyclical component.

\subsection{Calibration}

The purpose of the model is to illustrate how the different features of the economic environment interact to determine optimal (from the point of view of the borrower) debt maturity. To this end, I chose a reasonable calibration that is not meant to mimic the U.S. situation but that produces reasonable values of the variables of interest. I assume that the interest rate is 5 percent and that the expected growth rate of the firm's income is 1 percent. The standard deviation of the growth rate is 20 percent, which is close to the standard deviation of a broad index of the stock market. In the base case, bondholders recover about 60 percent of the value of the firm in the case of default $(\delta=0.4)$ and the fixed cost, $F$, is set to 5 . I consider a firm that has a financing need of $\bar{K}=65$. 


\section{Figure 1}

\section{Debt Structure, Firm Value, and Yield to Maturity (Low x)}
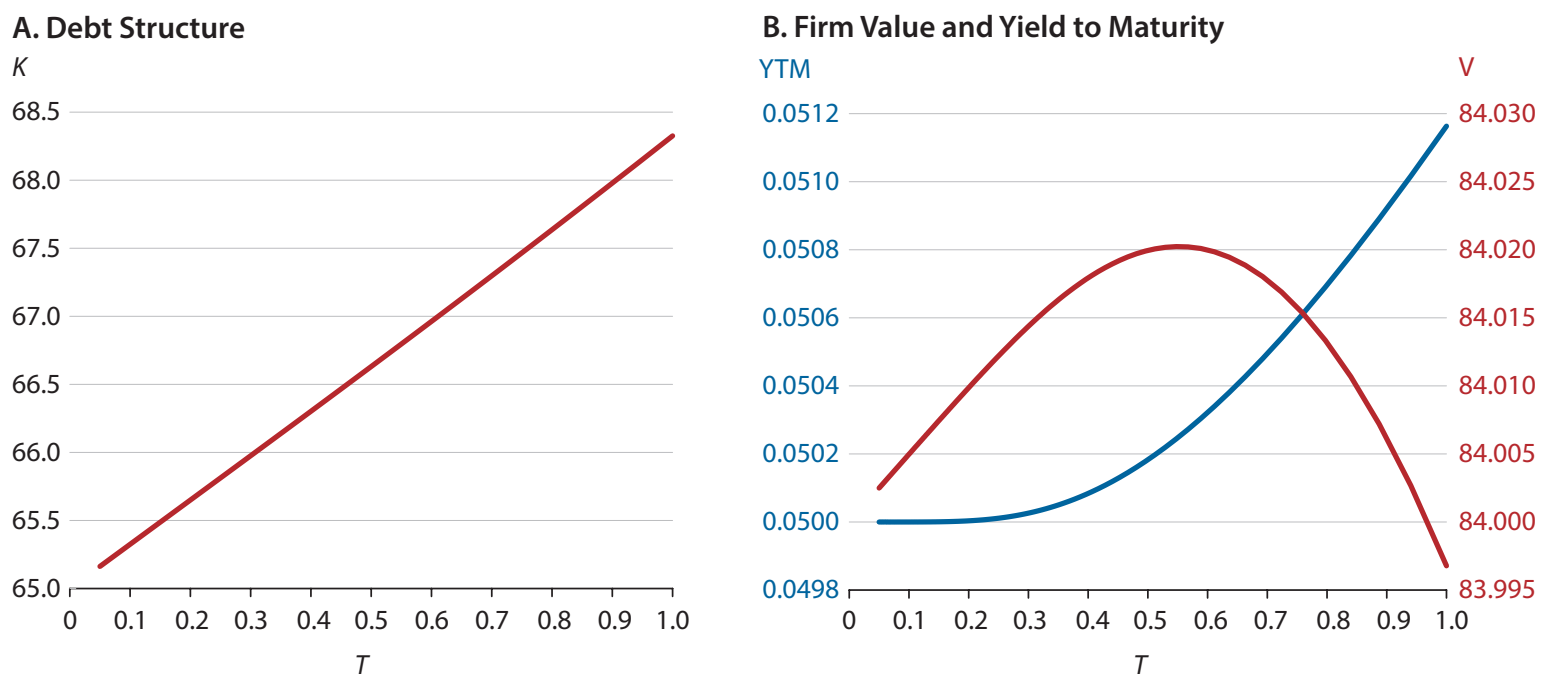

NOTE: YTM, yield to maturity; $V$, firm value.

SOURCE: Author's calculations.

\subsection{A First Look at the Options}

Before I discuss the optimal debt structure, it is useful to see the set of options that the firm had available when choosing a particular bond. Panel A of Figure 1 contains the set of pairs $(T, K)$ that raise a given amount of revenue (in this case, $\bar{K}=65$ ) when $x$ is relatively low $(x=6)$. As expected, if the firm chooses to issue longer debt, it has to offer a higher face value. Panel B shows the consequences of those possibilities for the value of the firm and the yield to maturity.

For this particular (low) value of net income, the optimal maturity is about 5.5 months. It is clear that the firm had the option of issuing longer (or shorter) debt but chooses not to. Moreover, by choosing shorter debt, the firm could have lowered the excess yield of the debt issued. However, value maximization does not imply excess yield minimization.

Figure 2 has similar information but for a higher level of earnings.

In this case, the optimal (in the sense of value maximization) maturity is close to four years. As in the previous case, the market was willing to purchase debt of different maturities provided the firm was willing to offer the necessary excess return.

What does an increasing yield as a function of maturity say about how face value changes with maturity? The yield to maturity of a bond that has a market value equal to $\bar{K}$ is

$$
y(T)=\left(\frac{K(T)}{\bar{K}}-1\right) \frac{1}{T},
$$




\section{Figure 2}

\section{Debt Structure, Firm Value, and Yield to Maturity (High $x$ )}
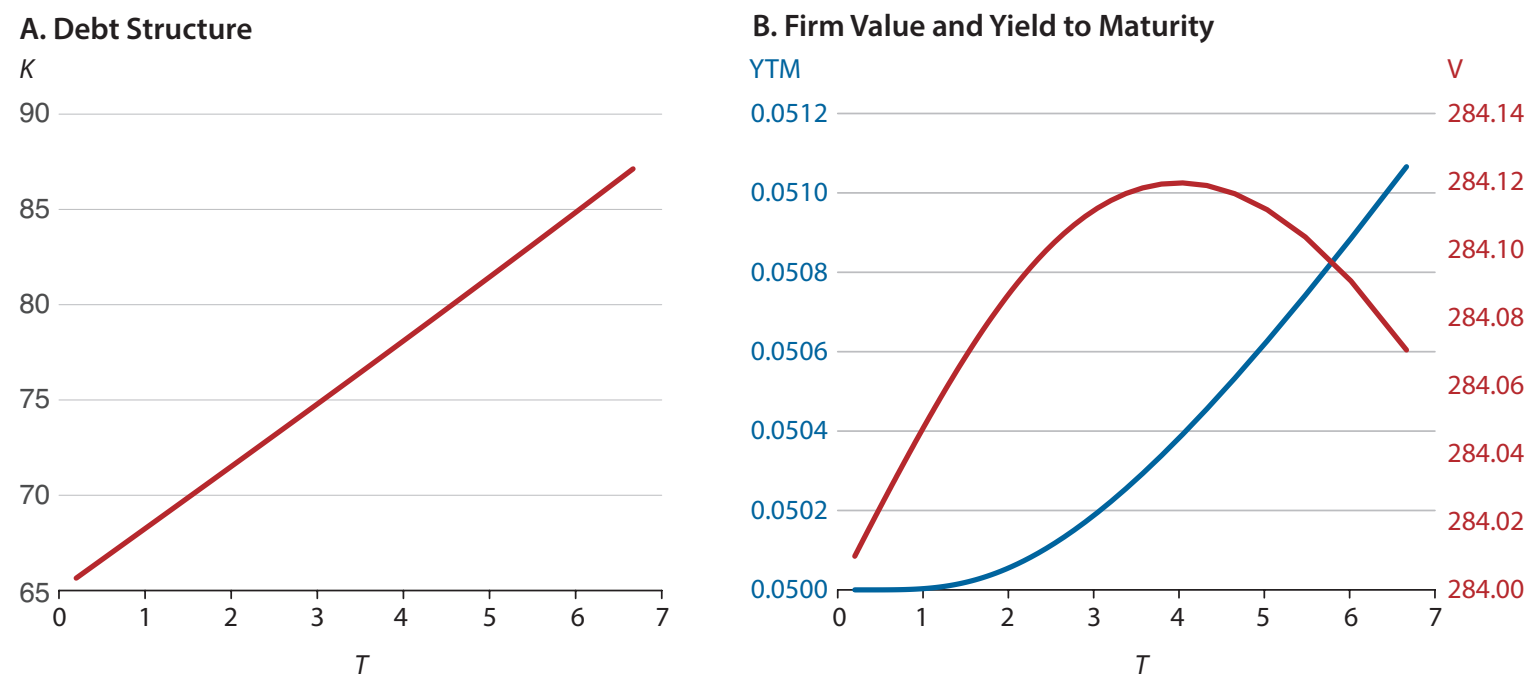

NOTE: YTM, yield to maturity; $V$, firm value.

SOURCE: Author's calculations.

where $K(T)$ depends on $(\bar{K}, x)$ as well as all other variables that have an effect on the value of the bond. If the function $y(T)$ is differentiable, then it is increasing in maturity if and only if

$$
K(T)<\bar{K}+K^{\prime}(T) T
$$

Since the function $K(T)$ must have the property that $\lim _{T \rightarrow 0} K(T)=\bar{K}$, the previous condition shows that the face value must be a concave function of maturity. Thus, the ratio of the face value to maturity is decreasing in the average maturity.

The model also illustrates the difficulties of using observed values of yields to estimate the term premium. As mentioned before, there is no "pure" term premium in this model. However, suppose that one had data on just the two bonds that are optimally chosen by two firms that are identical except for the level of current earnings. Both bonds raise exactly the same amount, $\bar{K}$, but have different maturities. Since the model is not calibrated, it implies very small excess yields. To make the argument transparent, I use the difference between the excess yield of a long-term bond with a 4-year maturity and a short-term bond with a halfyear maturity.

I define the "observed" term premium as the difference between the excess yields for the bonds that are actually issued. In this example, this difference is (after adjusting units) 13. I can now ask, what would have been the excess yield if the low-net-income firm (i.e., when $x=6$ ) had chosen to issue a 4-year bond instead of a half-year bond? In this example, the equivalent value is 70 . The same calculation for the high- $x$ firm yields 38 . Thus, I conclude that, for these examples, what could be called the true "term structure" is steeper the lower the current level 
Figure 3

\section{Leverage and Optimal Debt Structure}
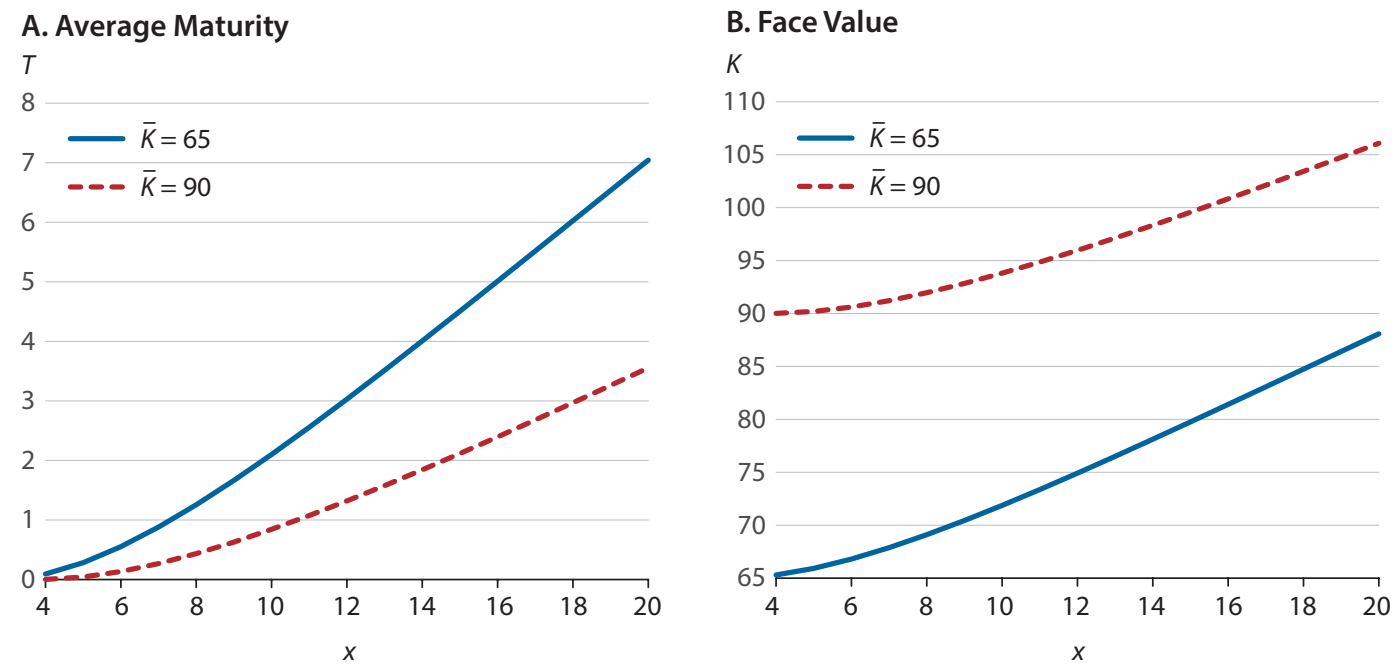

SOURCE: Author's calculations.

of income and that the observed term structure-which reflects optimal maturity choice-is much flatter.

\subsection{Optimal Debt Structure: Cyclical Effects}

What is the optimal debt structure as defined by face value, $K$, and expected maturity, $T$ ? What are the factors that influence the choice of debt structure by a firm? I first look at what I view as a cyclical component, that is, how the optimal debt structure changes as net earnings change. The intuitive interpretation is that higher earnings are associated with good times (and in this model larger firms).

Figure 3 reports for average maturity (Panel A) and face value (Panel B) the optimal debt structure $(T, K)$ as a function of net income, $x$, for two levels of financing requirements (i.e., $\bar{K}): 65$ and 90 . For reference, when $x$ is less than 10, the resulting leverage is close to 100 percent, while when $x$ is equal to 10 , the implied leverage decreases to 50 percent. Overall, I view the results of when $x$ is less than 10 as capturing the optimal debt structure for highly indebted firms (or countries) and when $x$ is greater than 10 as being more representative of the case in which financing needs are low.

As expected, firms with better prospects-as measured by their current earnings $x$-issue longer debt. This finding is consistent with the previous discussion that showed that higher current earnings - which in this model also correspond to higher future expected earningsreduce the cost of default and allow a firm to postpone paying the cost of repaying the debt. The results show that a higher level of leverage-captured here by a higher value of funds that the firm has to raise-is associated with shorter maturity. The difference in leverage-as 
captured by the difference between 65 and 90-also has a large impact on optimal maturity when net earning, $x$, are high, but the impact tends to disappear as net earning become low. The results suggest that firms with low levels of earnings choose short maturities even when the market value of the debt they issue varies significantly.

Since higher $x$ is associated with longer maturities, the face value of the bond must increase as well. This is illustrated in Panel B of Figure 3.

Figure 4 shows the yield to maturity of debt issued by a firm. Note that the yield is increasing in $x$. As I discussed in the previous section, at each point $x$, the firm has multiple options in terms of debt structure - combinations of $(T, K)$ that raise the required funds but differ in yield to maturity. The results show that the firm does not choose the debt structure that minimizes the excess yield. At any level of net earnings, the market is willing to lend to the firm at a lower premium if the firm chooses debt with a shorter maturity. The optimal choice-the choice that maximizes the value of the firm-does not minimize the excess yield. As the situation of the firm improves ( $x$ increases), the firm chooses to issue longer debt and to pay a higher return on that debt.

One could easily merge the data from Figures 3 and 4 to create a market-based "term structure" but, as discussed in the previous section, this cannot be used to estimate the costs of debt of different maturities issued by the same firm. In general, I expect that the termstructure curve faced by a firm - at, say, a given $x$-to be steeper than the one that emerges from looking at the optimally chosen debt structure.

\subsection{Optimal Debt Structure: The Impact of Uncertainty}

Figure 5 presents the results on the impact of uncertainty, $\sigma$, on average maturity, $T$ (Panel A), and face value, $K$ (Panel B).

As in the case of differences in financing needs, the responses are fairly nonlinear. Borrowers that operate in more-volatile environments find it optimal to issue shorter debt and, somewhat mechanically, debt with lower face value. For example, at low levels of net earnings (say for $x<6$ ), firms that operate in a low-uncertainty environment (i.e., $\sigma=0.2$, the blue line) and firms that operate in a high-uncertainty environment (i.e., $\sigma=0.4$, the red line) both issue very short-term debt (maturity less than a year). However, for high levels of net earnings (which also have low levels of leverage), while firms in the low-uncertainty environment issue debt with an average maturity of over five years, firms in the high-uncertainty environment 
Figure 5

\section{Uncertainty and Optimal Debt Structure}
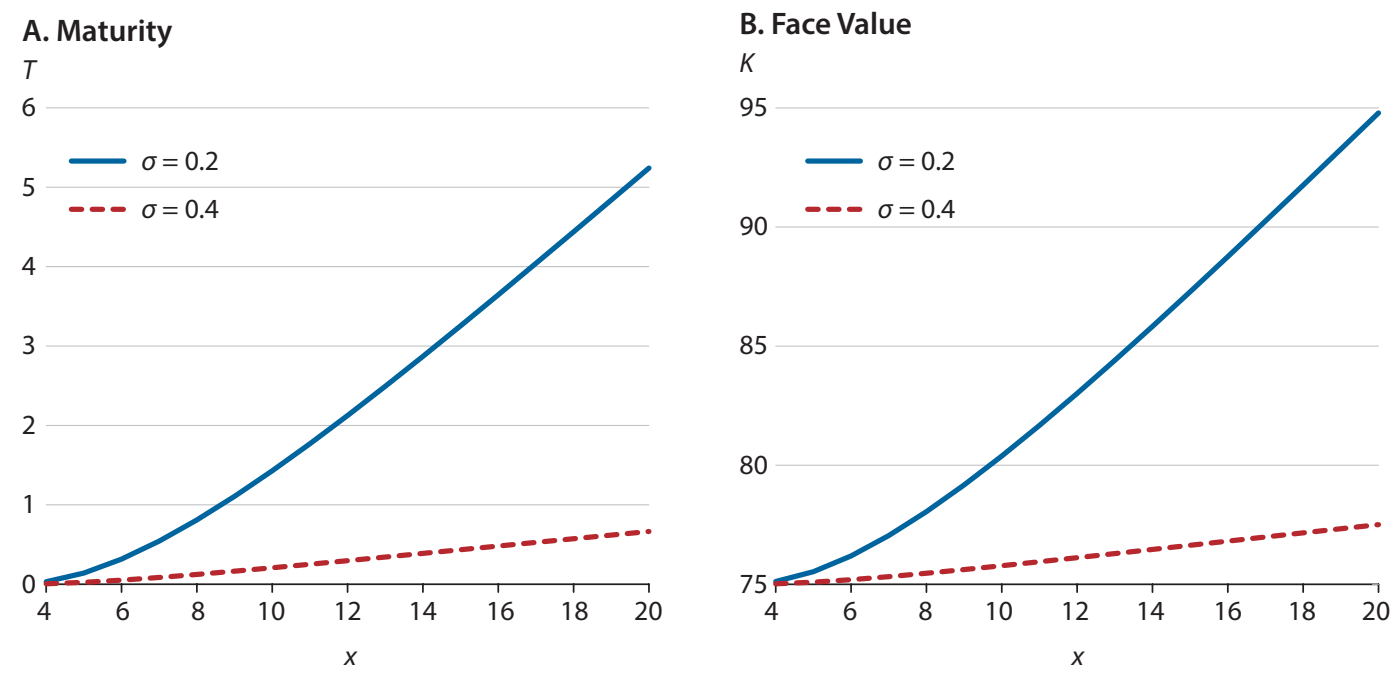

SOURCE: Author's calculations.

still issue debt with an average maturity Figure 6

of less than a year. Put differently, maturity responds more elastically to changes in net income at low levels of uncertainty. When volatility is high, these results suggest that the cyclical component (the value of $x$ ) has a small impact on maturity. $\underline{9}$

Figure 6 shows that, somewhat surprisingly, debt issued by the borrower in the low-uncertainty environment has a higher yield. Thus, uncertainty and excess yield move in the opposite directions. To understand what drives this result, consider the forces at work when volatility increases. On the one hand, higher uncertainty increases risk and tends to increase yields. However, the firm with more-uncertain revenue issues shorter

\section{Uncertainty and Yield to Maturity}

YTM

0.05035

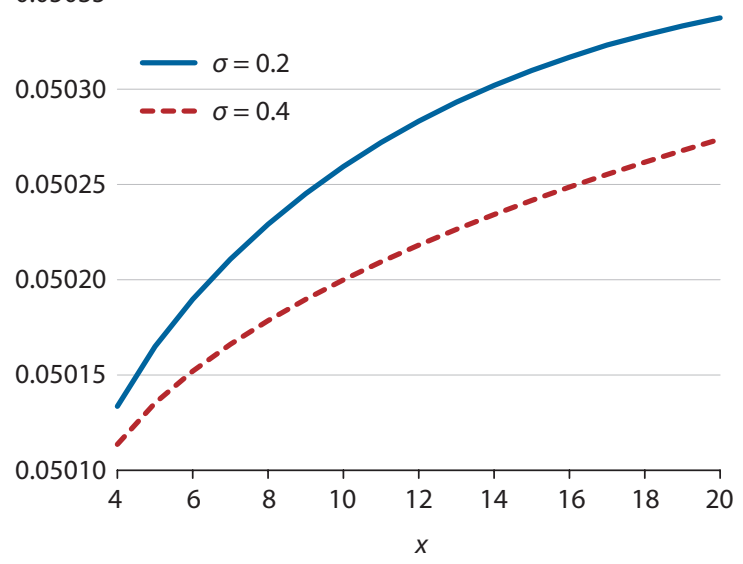

NOTE: YTM, yield to maturity.

SOURCE: Author's calculations. debt and this second effect-which moves yields in the opposite direction-dominates. Thus, it is the endogenous choice of the borrower that determines the yield. 
Figure 7

Asset Saleability, Growth, and the Optimal Debt Structure
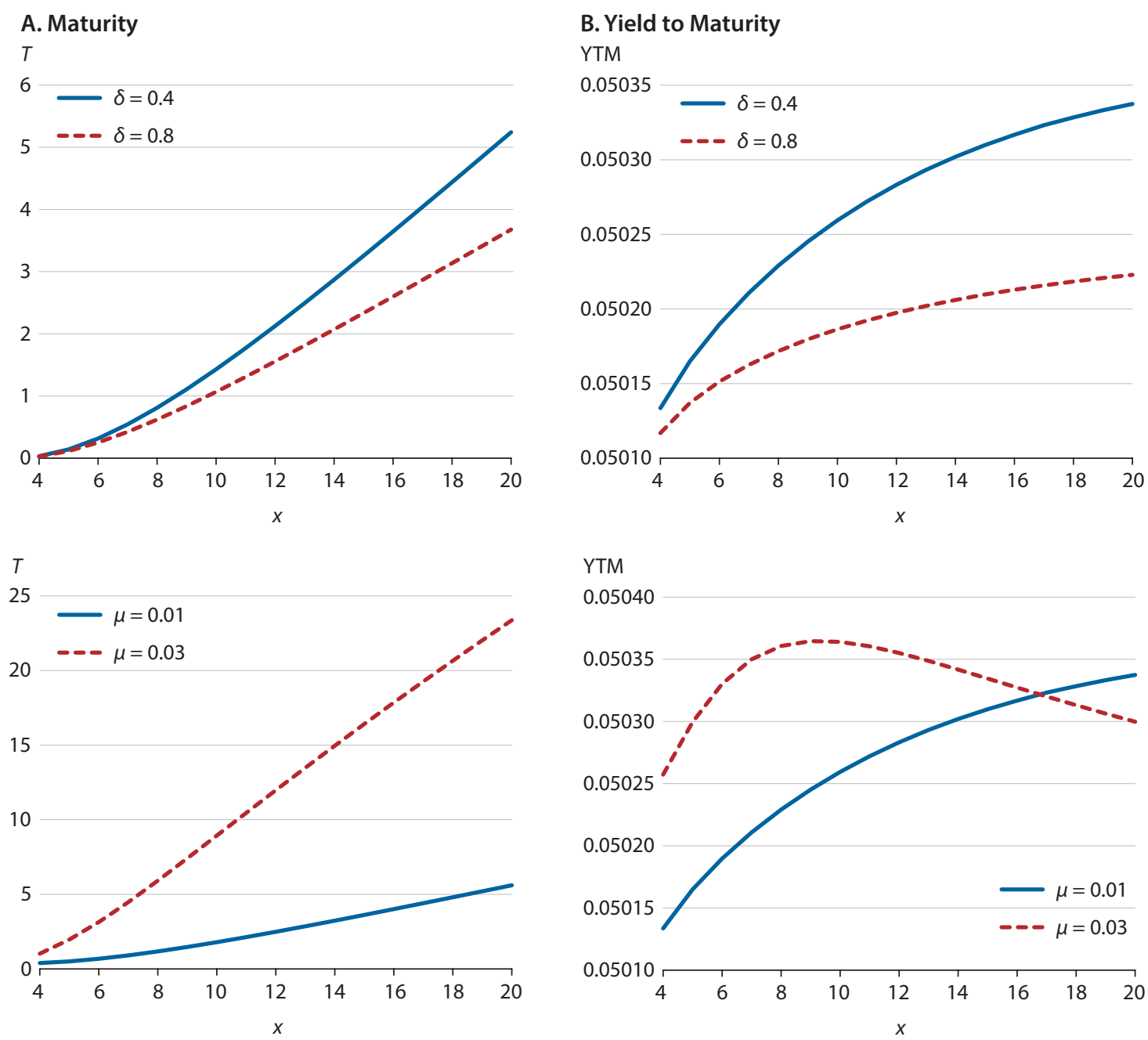

NOTE: YTM, yield to maturity.

SOURCE: Author's calculations.

\subsection{Optimal Debt Structure: Collateral and Growth Prospects}

The impact of the value of collateral and growth prospects on the average maturity and yield are summarized in the four panels of Figure 7. Higher collateral results is longer debt due to the lower cost of a default. As in the previous case, maturity is the dominating force because the yield is also higher (even though the risk is lower).

The impact of higher growth is as expected: Firms with better growth prospects issue longer debt. The implication for yield to maturity is not monotone. There are two forces at work: Higher growth lowers the risk of default, which works in the direction of lowering the 
yield demanded by the market. However, high-growth firms issue longer-term debt, which works in the opposite direction. For relatively low values of net earnings, the second effect dominates, but for high values of $x$, the lower probability of default is the dominant force because both types of firms (high and low growth) optimally choose to issue bonds with the same maturity.

\section{CONCLUSION}

In this article, I presented a very simple model that sheds light on some of the factors that influence the choices of debt structure, maturity, and face value, by borrowers that have a stochastic earnings stream. The model is designed so that financial markets and borrowers share exactly the same discount factor and, to prevent strategic forces that pitch holders of different maturities against each other, I look at the case of a single bond. Because of the simplicity of the model, the results are suggestive, but more work needs to be done before taking the model to the data.

Several findings are broadly consistent with the evidence:

(i) The higher the level of income, the longer the maturity of the debt. In the model, this captures the tradeoff between longer debt (that increases the price of risk) and short debt (that incurs a payment cost that can be delayed).

(ii) Firms in more-uncertain environments issue shorter-term debt. However, higher uncertainty does not translate into a higher price of risk, as measured by the excess yield to maturity over the (risk free) rate. The reason is that, faced with higher uncertainty, firms issue shorter-term debt, which lowers the return demanded by the market. Thus, it would be erroneous to use yields (say, relative to the risk-free rate) when estimating default risk since in this simple model there is an endogenous "term premium like" component of the yield as well.

(iii) Better collateral and higher growth prospects result in firms choosing longer maturities. The impact on the yield to maturity is ambiguous. In general, better collateral is associated with a higher yield to maturity because of the longer debt. Higher growth is associated with higher yields for firms with low income, but lower yields for firms with high income.

This simple model suggests that simplistic policy recommendations of the form "it is always better to borrow long" fail to understand that, even in situations in which it is possible to borrow long, the firm may choose to borrow short because longer maturities have associated prices of risk that are endogenous. More relevant to interpreting both the evidence on firm borrowing and sovereign borrowing is that when income is low, firms/countries choose shorter debt-and not the other way around. 


\section{APPENDIX}

In this appendix, we derive the values of the firm and the debt as given by equations (2) and (3).

\section{A.1 The Value of the Firm}

The problem of the firm has an associated Hamilton-Jacobi-Bellman equation given by

$$
\begin{aligned}
r V(x ; T, K)= & x+\frac{\partial V}{\partial x} \mu(x)+\frac{\partial^{2} V}{\partial x^{2}} \frac{\sigma^{2}(x)}{2}+ \\
& \frac{1}{T}\left[\max \left(\frac{x}{r-\mu}-(K+F), 0\right)-V(x, \theta)\right] .
\end{aligned}
$$

It is standard to show that the solution to the previous equation is of the form

$$
V(x, T, K)=\left\{\begin{array}{ll}
V_{H}(x, T, K) & x \geq \bar{x}(K) \\
V_{L}(x, T, K) & x \leq \bar{x}(K)
\end{array} .\right.
$$

The value of the firm is

$$
\begin{aligned}
& V_{H}(x, T, K)=\frac{x}{r-\mu}-\frac{(K+F)}{1+r T}+\bar{V}_{H}^{1}\left(\frac{x}{\bar{x}(K)}\right)^{\lambda_{1}}, \\
& V_{L}(x, T, K)=\frac{T x}{1+(r-\mu) T}+\bar{V}_{L}^{2}\left(\frac{x}{\bar{x}(K)}\right)^{\lambda_{2}},
\end{aligned}
$$

where $\lambda_{1}\left(\lambda_{2}\right)$ is the negative (positive) root of

$$
r+\frac{1}{T}-\lambda \mu=\frac{\sigma^{2}}{2} \lambda(\lambda-1)
$$

and the constants are given by

$$
\begin{aligned}
& \bar{V}_{H}^{1}=\frac{1}{\lambda_{2}-\lambda_{1}}\left[\left(\lambda_{2}-1\right) \frac{T(r-\mu) K}{1+T(r-\mu)}+\frac{T K}{1+T r}\left(r+\frac{1}{T}-\lambda_{2} r\right)+\frac{\lambda_{2} F}{1+T r}\right], \\
& \bar{V}_{H}^{1}=\frac{1}{\lambda_{2}-\lambda_{1}}\left[\left(\lambda_{1}-1\right) \frac{T(r-\mu) K}{1+T(r-\mu)}+\frac{T K}{1+T r}\left(r+\frac{1}{T}-\lambda_{1} r\right)+\frac{\lambda_{1} F}{1+T r}\right] .
\end{aligned}
$$

\section{A.2 The Market Value of the Debt}

The market value of a $(T, K)$ bond depends not only on its maturity but also on its default probability. The relevant Hamilton-Jacobi-Bellman equation whose solution is the market value of the bond is

$$
r B(x ; T, K)=b+\frac{\partial B}{\partial x} \mu(x)+\frac{\partial^{2} B}{\partial x^{2}} \frac{\sigma^{2}(x)}{2}+T\left[R_{B}(x, K, \delta)-B(x, \theta)\right],
$$


where

$$
R_{B}(x, K, \delta)= \begin{cases}K & \text { if } x \geq \bar{x}(K) \\ \frac{(1-\delta) x}{r-\mu} & \text { if } x<\bar{x}(K)\end{cases}
$$

One can show that the solution to this equation can be described as simple functions that vary depending on which "branch" the value of net earnings is. Formally, the solution is of the form

$$
B(x, T, K)=\left\{\begin{array}{ll}
B_{H}(x, T, K) & x \geq \bar{x}(K) \\
B_{L}(x, T, K) & x \leq \bar{x}(K)
\end{array} .\right.
$$

The functions $B_{H}(x, T, K)$ and $B_{L}(x, T, K)$ are given by

$$
B_{H}(x, T, K)=\frac{K}{1+T r}+\bar{B}_{H}^{1}\left(\frac{x}{\bar{x}(K)}\right)^{\lambda_{1}}, \text { for } x \geq \bar{x}(K),
$$

and

$$
B_{L}(x, T, K)=\frac{(1-\delta)}{1+T(r-\mu)} \frac{x}{r-\mu}+\bar{B}_{L}^{2}\left(\frac{x}{\bar{x}(K)}\right)^{\lambda_{2}}, \text { for } x \leq \bar{x}(K)
$$

The constants are

$$
\begin{aligned}
& \bar{B}_{H}^{1}=\frac{K}{1+\operatorname{Tr}} \frac{1}{\lambda_{2}-\lambda_{1}}\left[\frac{\lambda_{2}(\mu T-\delta(r T+1))-(r T+1)(1-\delta)}{1+T(r-\mu)}\right] \\
& \bar{B}_{L}^{2}=\frac{K}{1+\operatorname{Tr}} \frac{1}{\lambda_{2}-\lambda_{1}}\left[\frac{\lambda_{1}(\mu T-\delta(r T+1))-(r T+1)(1-\delta)}{1+T(r-\mu)}\right] .
\end{aligned}
$$

\section{A.3 The Price of Risk}

The definition of the price of risk associated with a bond is the value of $P$ that accounts for the difference between the market price of a bond, $B$, and the price in the absence of risk, $B^{*}$. Formally,

$$
\frac{B(x, T, K)}{B^{*}(T, K)}=(1-P(x, T, K)) .
$$

Since the market value of a bond depends on whether it is in the money (i.e., $x \geq \bar{x}(K)$ ) or out of the money (i.e., $x<\bar{x}(K)$ ), there are two corresponding prices of risk: $P_{H}$ and $P_{L}$, respectively. Using the previous results on bond prices, it follows that

$$
P_{H}(x, T, K)=\Phi^{H}(T, K)\left(\frac{x}{\bar{x}(K)}\right)^{\lambda_{1}\left(T, \sigma^{2}\right)},
$$


where

$$
\Phi^{H}(x, T, K)=\frac{\phi_{N}\left(\lambda_{2} ; T, \sigma^{2}\right)}{2 \phi_{D}\left(T, \sigma^{2}\right)}
$$

and

$$
\begin{gathered}
\phi_{D}\left(T, \sigma^{2}\right)=\left[\left(\frac{1}{2}-\frac{\mu}{\sigma^{2}}\right)^{2}+2 \frac{(1+r T)}{T \sigma^{2}}\right]^{1 / 2}, \\
\phi_{N}\left(\lambda_{2} ; T, \sigma^{2}\right)=\frac{(1+r T)\left(1-\delta+\lambda_{2}\left(T, \sigma^{2}\right) \delta\right)-\lambda_{2}\left(T, \sigma^{2}\right) \mu T}{1+(r-\mu) T}
\end{gathered}
$$

and

$$
\lambda_{2}\left(T, \sigma^{2}\right)=\left(\frac{1}{2}-\frac{\mu}{\sigma^{2}}\right)+\phi\left(T, \sigma^{2}\right)>1
$$

and

$$
\lambda_{1}\left(T, \sigma^{2}\right)=\left(\frac{1}{2}-\frac{\mu}{\sigma^{2}}\right)-\phi\left(T, \sigma^{2}\right)<0 .
$$

It is possible to show that

$$
\left(\frac{x}{\bar{x}(K)}\right)^{\lambda_{1}\left(T, \sigma^{2}\right)}=E\left[e^{-r T_{\bar{x}(K)}} \mid x\right] .
$$

This implies that

$$
P_{H}(x, T, K)=\Phi^{H}(T, K) E\left[e^{-r T_{\bar{x}(K)}} \mid x\right],
$$

which is equation (4) in the text.

In the case of a bond that is out of the money, $x \leq \bar{x}(K)$, the price of risk is given by

$$
P_{L}(x, T, K)=1-\underbrace{\frac{(1-\delta) x}{(r-\mu) K} \frac{1+r T}{1+(r-\mu) T}}_{+}+\frac{\phi_{N}\left(\lambda_{1} ; T, \sigma^{2}\right)}{2 \phi_{D}\left(T, \sigma^{2}\right)}\left(\frac{x}{\bar{x}(K)}\right)^{\lambda_{2}\left(T, \sigma^{2}\right)} .
$$




\section{NOTES}

1 It turns out that allowing for more general debt that includes coupon payments does not expand the set of options relative to the pure discount bond.

$\underline{2}$ This is the mechanism in Broner, Lorenzoni, and Schmukler (2013).

3 Most of the empirical literature on determinants of debt maturity uses data on publicly traded companies. Ideally, one would like to analyze data on all firms, but available balance sheet data on non-traded firms are very limited.

4 This is quite different from the risk-aversion mechanism in Broner, Lorenzoni, and Schmukler (2013).

5 Manuelli and Sanchez (2019) study a more general version of the model with different regimes, more general debt instruments, and refinancing.

$\underline{6}$ Even though in this simple version uncertainty is exogenous, it is possible to interpret a higher level of $\sigma$ as driven in part by uncertainty about government policies.

$\underline{7}$ Formally, the elasticity converges to $\lambda_{1}\left(T, \sigma^{2}\right)$ as $x$ goes to infinity.

8 The uncertainty can be either the result of the type of industry that the firm operates in or the consequence of government policies that result in higher variability in the growth rate of a firm's earnings.

9 To the extent that volatility characterizes a given market, the results imply that a cross section of the expected maturity of the debt issued by firms, controlling for the amount raised, does not vary much in highly volatile markets and the opposite is true in more-stable markets.

\section{REFERENCES}

Aguiar, M.; Amador, M.; Hopenhayn, H. and Werning, I. “Take the Short Route: Equilibrium Default and Debt Maturity." Econometrica, March 2019, 87(2), pp. 423-62; https://doi.org/10.3982/ECTA14806.

Arellano, C. and Ramanarayanan, A. "Default and the Maturity Structure in Sovereign Bonds." Staff Report 410, Federal Reserve Bank of Minneapolis, 2013.

Benmelech, E. and Dvir, E. "Does Short-Term Debt Increase Vulnerability to Crisis? Evidence from the East Asian Financial Crisis." NBER Working Paper No. 17468, National Bureau of Economic Research, 2011; https://doi.org/10.3386/w17468.

Broner, F.; Lorenzoni, G. and Schmukler, S. "Why Do Emerging Economies Borrow Short Term?" Journal of the European Economic Association, January 2013, 11 (Issue Suppl. 1), pp. 67-100; https://doi.org/10.1111/j.1542-4774.2012.01094.x.

Brunnermeier, M. and Oehmke, M. “The Maturity Rat Race." Journal of Finance, 2013, 68(2), pp. 483-521; https://doi.org/10.1111/jofi.12005.

Chen, H.; Cui, R.; He, Z. and Milbradt, K. "Quantifying Liquidity and Default Risks of Corporate Bonds over the Business Cycle." Unpublished manuscript, 2017; https://doi.org/10.1093/rfs/hhx107.

Diamond, D. “Debt Maturity and Liquidity Risk." Quarterly Journal of Economics, 1991, 106(3), pp. 709-37; https://doi.org/10.2307/2937924.

Dvorkin, M.; Sanchez, J.; Sapriza, H. and Yurdagul, E. "News, Sovereign Debt Maturity, and Default Risk." Working Paper No. 2018-033, Federal Reserve Bank of St. Louis, 2018; https://doi.org/10.20955/wp.2018.013.

Kacperczyk, M. and Schnabl, P. "When Safe Proved Risky: Commercial Paper During the Financial Crisis of 2007-2009." Journal of Economic Perspectives, 2010, 24(1), pp. 29-50; https://doi.org/10.1257/jep.24.1.29.

Leland, H. and Toft, K. "Optimal Capital Structure, Endogenous Bankruptcy, and the Term Structure of Credit Spreads." Journal of Finance, 1996, 51(3), pp. 987-1019; https://doi.org/10.1111/j.1540-6261.1996.tb02714.x.

Manuelli, R. and Sanchez, J. "Endogenous Debt Maturity: Liquidity Risk vs Default Risk." Unpublished manuscript, 2019; https://doi.org/10.20955/wp.2018.034.

Rodrik, D. and Velasco, A. "Short-Term Capital Flows." NBER Working Paper No. 7364, National Bureau of Economic Research, 1999; https://doi.org/10.3386/w7364. 